\title{
Diurnal differences in milk composition and its influence on in vitro growth of Staphylococcus aureus and Escherichia coli in bovine quarter milk
}

\author{
S. W. F. Eisenberg, ${ }^{* 1}$ E. M. Boerhout, †‡ L. Ravesloot, ${ }^{*}$ A. J. J. M. Daemen, ${ }^{*}$ L. Benedictus, $\ddagger$ \\ V. P. M. G. Rutten, $¥ \S$ and A. P. Koets*\# \\ *Department of Farm Animal Health, Faculty of Veterinary Medicine, Utrecht University, Yalelaan 7, 3584 CL Utrecht, the Netherlands \\ †Ruminant Research and Development, MSD Animal Health, Wim de Körverstraat 35, 5830 AA Boxmeer, the Netherlands \\ ‡Department of Infectious Diseases and Immunology, Faculty of Veterinary Medicine, Utrecht University, Yalelaan 1, 3584 CL Utrecht, \\ the Netherlands \\ $\S$ Department of Veterinary Tropical Diseases, Faculty of Veterinary Science, University of Pretoria, Private Bag X04, Onderstepoort 0110, \\ South Africa \\ \#Department of Bacteriology and Epidemiology, Central Veterinary Institute part of Wageningen UR, Edelhertweg 15, PO Box 65, \\ 8200 AB Lelystad, the Netherlands
}

\begin{abstract}
In experimental intramammary inoculation studies, it has been observed that mastitis susceptibility is influenced, among others, by cow factors. To identify milk characteristics leading to these differences, quarter milk samples of morning and evening milk were collected and analyzed for their composition (protein, fat, lactose, urea, lactoferrin, lactoperoxidase, and $\beta$-lactoglobulin concentrations), somatic cell count, and antibodies against Staphylococcus aureus. Furthermore, in vitro growth of $S$. aureus and Escherichia coli in fresh quarter milk samples was determined. All measured parameters differed significantly between quarters and also between morning and evening milk with the exception of lactose levels. In addition, quantitative growth of $S$. aureus and $E$. coli was significantly different in morning milk compared with evening milk. Mixed model analysis revealed that replication of $S$. aureus was negatively associated with the presence of fat, S. aureus-specific $\mathrm{IgG}_{1}$ antibodies, contamination of the milk sample and morning milk. Replication of $E$. coli was negatively associated with fat concentrations, and positively associated with morning milk. The significant difference between morning and evening milk supports the theory that changes in milk composition influence bacterial growth. Although all determined milk components differed significantly between quarters and in time no significant association with bacterial growth could be identified with the exception of fat for both studied species and $\operatorname{IgG}_{1}$ titers for $S$. aureus. The negative association of fat with bacterial growth was assumed to occur due to activation of lipolysis by
\end{abstract}

Received December 14, 2015.

Accepted March 18, 2016.

${ }^{1}$ Corresponding author: s.w.f.eisenberg@gmx.de milk handling and can most likely be neglected for in vivo relevance. The fact that $S$. aureus-specific $\operatorname{IgG}_{1}$ titers were negatively associated with $S$. aureus growth in vitro encourages the ongoing effort to develop a vaccine against $S$. aureus-induced mastitis.

Key words: milk composition, bovine, Staphylococcus aureus, Escherichia coli

\section{INTRODUCTION}

Mastitis in cattle is a worldwide problem in dairy farming with a major effect on animal welfare, life span, and milk production (Keefe, 2012; Peton and Le Loir, 2014). When mastitis occurs, treatment with antibiotics is often necessary. However, prevention of the invasion of the udder rather than curing the subsequent infection is the ultimate goal to restrain the development of antibiotic resistance (Smith et al., 2006). Cow factors as age, lactation stage, teat anatomy and condition, leaking milk, and previous infection have been identified as risk factors for mastitis under field conditions most likely by influencing bacterial invasion of the udder and the general immune function of the cow (Schukken et al., 1991; Zadoks et al., 2001; Breen et al., 2009). Improvement of management factors and function of the milking equipment are important efforts to decrease the incidence of mastitis (Schukken et al., 1991; Green et al., 2007). In addition, experimental studies have shown that invasion of a quarter by bacterial species does not always lead to clinical infection, implicating differences in susceptibility between cows and quarters (Bramley, 1976; Schukken et al., 1999). In observational as well as experimental studies, quarter-specific susceptibility has also been observed when position of the quarter and anatomical differences were associated with susceptibility (Slettbakk et al., 1995; Zadoks et al., 2001). Milk composition may also influence the susceptibility to 
infection. Milk-specific risk factors identified under experimental conditions are SCC (Bramley, 1976; Schukken et al., 1999), fat concentration, and for Staphylococcus aureus, the concentration of $S$. aureus-specific $\mathrm{IgG}_{1}$ (Boerhout et al., 2016). In addition, lactoferrin, $\beta-\mathrm{LG}$, and lactoperoxidase are known for their antibacterial and protective properties in milk (Bramley, 1976; Schukken et al., 1999; Piccinini et al., 2005; Hyvonen et al., 2010; Chaneton et al., 2011) and differences in protein, fat, lactose, and urea concentrations may influence bacterial growth in milk by changing the local environment. Normally, milk composition is measured per cow per day by analyzing a sample consisting of equal amounts of morning and evening milk of all 4 quarters. As a result, quarter- and time-specific variation levels off. However, it is known that, for example, SCC change in a circadian rhythm and also differ between quarters, which lead to differences in quarter susceptibility to infection (White and Rattray, 1965; Barkema et al., 1999; Schukken et al., 1999). Because the local defense system of the udder does not only consist of leukocytes present in milk but also includes molecular factors of the innate and adaptive immune system, concentrations of these factors are, most likely, also different between quarters and change over time.

Therefore, the objective of this study was to identify quarter-specific differences in milk composition and differences between morning and evening milk. In addition, in vitro growth of $S$. aureus and Escherichia coli, 2 major mastitis-causing pathogens, in fresh milk samples was measured and their growth patterns in relation to levels of milk factors potentially involved in altering bacterial growth were compared.

\section{MATERIALS AND METHODS}

\section{Milk Collection}

The dairy herd of the Faculty of Veterinary Medicine (Utrecht, the Netherlands) consisting of 47 cows, mainly of the Holstein breed, was housed in a freestall housing system. Cows were fed a diet based on grass and corn silage, beet pulp, and concentrate that was formulated to meet the dietary requirements for lactating dairy cows. Corn silage was administered after milking twice daily (0800 and $1900 \mathrm{~h}$ ). Concentrate was administered via an automated feeding system, whereas grass silage and drinking water were supplied ad libitum. Milk volume was determined by the automatic milking system. Quarter milk samples of all cows were collected during evening and morning milking (with a 13 -h time interval) in parallel with test day samples (TD). Quarter milk samples $(50 \mathrm{~mL})$ were collected by hand after foremilking. Conventional TD samples were collected automatically and consisted of a representative composite sample of the 4 quarters and an equal volume of morning milk and evening milk. Both quarter samples and TD samples were analyzed for milk composition (fat percentage, total protein percentage, lactose level, and urea concentration) and quality (SCC) by a commercial milk quality assurance laboratory (Qlip, Zutphen, the Netherlands). Aliquots of the quarter milk samples were stored at $-20^{\circ} \mathrm{C}$ until determination of lactoferrin, lactoperoxidase, and $\beta$-LG concentrations and levels of $S$. aureus-specific antibodies. Aliquots of fresh milk were used for the in vitro growth assay and for bacterial culture. For IgG purification, colostrum of 4 cows of the dairy herd was collected on the day of parturition and analyzed for the presence of $S$. aureusspecific $\operatorname{IgG}_{1}$ antibodies as described below.

\section{In Vitro Growth Assay}

For the in vitro growth assay $S$. aureus (strain Newbould 305) and an E. coli field isolate were used. Both bacteria were grown in sterile brain-heart infusion medium (Oxoid, Wessel, Germany) overnight under aerobic conditions, shaking gently at $37^{\circ} \mathrm{C}$. The overnight culture was centrifuged twice at 4,000 $\times g$ for $15 \mathrm{~min}$ at room temperature and the pellet was resuspended in $20 \mathrm{~mL}$ of sterile PBS (Lonza, Basel, Switzerland). Of the bacterial suspension, aliquots of $300 \mu \mathrm{L}$ were stored at $-20^{\circ} \mathrm{C}$ in microcentrifuge tubes. To determine bacterial load, 3 aliquots were thawed and 10-fold serial dilutions in PBS were prepared. The serial dilutions $(50 \mu \mathrm{L})$ were plated on sheep blood agar plates and incubated overnight at $37^{\circ} \mathrm{C}$ and $5 \% \mathrm{CO}_{2}$. Then, colonies were counted and colony-forming units per milliliter were calculated. For the in vitro growth assay, an aliquot of $S$. aureus and E. coli suspension was thawed and diluted as determined earlier to achieve a bacterial concentration of $600 \mathrm{cfu} / \mathrm{mL}$.

For in vitro growth assessment, $100 \mu \mathrm{L}$ of each quarter milk sample was added into a U-bottom 96well polystyrene microtiter plate (Costar 9018, Corning B.V. Lifesciences, Amsterdam, the Netherlands). The remaining milk was stored at $4^{\circ} \mathrm{C}$ until bacterial culture. Bacterial suspensions $(50 \mu \mathrm{L})$ were added to milk samples and plates were incubated for $3 \mathrm{~h}$ at $37^{\circ} \mathrm{C}$ and $5 \% \mathrm{CO}_{2}$. After incubation, samples were mixed by pipetting and $50 \mu \mathrm{L}$ from each well was plated on a sheep blood agar plate. In addition, $50 \mu \mathrm{L}$ of each fresh milk sample was plated on a sheep blood agar plate to check for bacterial contamination present before the in vitro growth assay. Following an overnight incubation at $37^{\circ} \mathrm{C}$ and $5 \% \mathrm{CO}_{2}$, colonies were counted. To 
identify the final number of colony-forming units added to the milk samples, $50 \mu \mathrm{L}$ of the initial bacterial suspension was directly plated on sheep blood agar plates and incubated overnight under the same conditions. Bacteria were presumptively identified by colony size, morphology, pigmentation, and type of hemolysis. The outcome was expressed as colony-forming units per plate. Growth of bacteria other than $S$. aureus or $E$. coli was noted and expressed as a binomial value $(0=$ no other bacteria grown; $1=$ other bacteria grown).

To study the specific influence of immunoglobulin concentration on in vitro growth of $S$. aureus, fresh quarter milk of 3 healthy (absence of clinical mastitis and other signs indicating disease, such as abnormal behavior, lack of appetite, and lameness) mid-lactation donor cows was spiked with purified IgG in a concentration ranging from 0.08 to $5 \mathrm{mg} / \mathrm{mL}$ and used as a template in the $S$. aureus in vitro growth assay. Of spiked and original milk samples, $100 \mu \mathrm{L}$ of milk was pipetted into a U-bottom 96-well polystyrene microtiter plate and in vitro growth was studied as described above. Analyses were performed in triplicate.

\section{S. aureus-Specific Antibody ELISA}

The $S$. aureus Reynolds CP strain is lacking a capsule and therefore lacking protein A (Albus et al., 1991). This strain was chosen for the antibody ELISA to prevent nonspecific reactions of immunoglobulins with protein A. Staphylococcus aureus Reynolds was grown in trypticase soy broth for $20 \mathrm{~h}$ at $39.5^{\circ} \mathrm{C}$ and inactivated by overnight incubation with $0.5 \%$ formalin. Bacteria were harvested by centrifugation and resuspended in PBS. Then, Nunc MaxiSorp plates (eBioscience, Hatfield, UK) were coated overnight at $4^{\circ} \mathrm{C}$ with $0.1 \mu \mathrm{g}$ of bacterin in $0.05 M$ carbonate-bicarbonate buffer $(120 \mu \mathrm{L}$; MSD-AH, Boxmeer, the Netherlands) and subsequently blocked with casein $(200 \mu \mathrm{L}$; MSDAH). Samples and positive control serum were tested in 2-fold serial dilutions $(100 \mu \mathrm{L})$ and incubated for $1 \mathrm{~h}$ at $37^{\circ} \mathrm{C}$. An in-house negative control serum was taken along in octaploid. As secondary antibody, horseradishperoxidase-conjugated sheep anti bovine $\operatorname{IgG}_{1}$ (Bethyl Laboratories Inc., Montgomery, TX) was used in a 1:2,000 dilution $(100 \mu \mathrm{L})$. Tetramethylbenzidine (MSD$\mathrm{AH})$ was used as a substrate $(100 \mu \mathrm{L})$ and reactions were stopped after an incubation of $10 \mathrm{~min}$ in the dark by adding $2 M$ sulfuric acid $(50 \mu \mathrm{L})$. Absorbance $(450$ $\mathrm{nm}$ ) was measured on a Tecan Sunrise device (Tecan Group Ltd., Männedorf, Germany) using XFluor4 Software Version V4.51-I4. Antibody titers were determined using CaSpEx Software AbendVertical version
0.11 V1 (MSD-AH, proprietary software) and defined as the $\log _{2}$ dilution of the sample that would give the same absorbance as the predefined cut-off. The cut-off was defined as 2 times the average OD of the negative controls. Antibody titers of all milk samples were determined.

\section{Detection of Lactoferrin, $\beta$-Lactoglobulin, and Lactoperoxidase}

Lactoferrin (LF) and $\beta$-LG concentrations were determined using commercially available ELISA kits (Bovine Lactoferrin and Bovine $\beta$-Lactoglobulin ELISA Quantification Set, Bethyl). The ELISA were performed according to the manufacturer's manual and outcomes expressed as $\mathrm{ng} / \mathrm{mL}$. Lactoperoxidase (LP) was detected using an in-house quantitative ELISA, which was performed as follows. A standard curve was prepared using bovine LP in a 2-fold dilution ranging from 0.078 to $5 \mathrm{U} / \mathrm{mL}$ (Sigma-Aldrich, St. Louis, MO). Milk and standard samples were diluted 1:50 in blocking buffer (Roche, Sigma-Aldrich) and $50 \mu \mathrm{L}$ was added into a flat-bottom microtiter plate (Costar). Tetramethylbenzidine was added $(100 \mu \mathrm{L})$ and reactions were stopped after an incubation of $15 \mathrm{~min}$ in the dark by adding $2 M$ sulfuric acid $(50 \mu \mathrm{L})$. The LP concentration was determined by measuring the absorbance at $450 \mathrm{~nm}$ using a spectrophotometer (Thermo Fisher Scientific Inc., Waltham, MA). The outcome was expressed as units per milliliter.

\section{Immunoglobulin G Purification from Colostrum and Titration in Milk Samples}

Immunoglobulin $\mathrm{G}$ was purified from delipidated colostrum by liquid affinity chromatography using HiTrap Protein G columns (GE Healthcare, Eindhoven, the Netherlands). The final concentration step, resulting in a concentration of $67 \mathrm{mg} / \mathrm{mL}$, was performed using a Vivaspin500 centrifugal concentrator (Sigma-Aldrich) according to the manufacturer's protocol.

\section{Statistical Analysis}

Data editing was done using Excel (Office 2010, Microsoft, Redmond, WA). The descriptive and statistical analyses were done using the SPSS statistical software package (IBM SPSS statistics 20.0, IBM, Armonk, NY). For graphical presentation of the data, GraphPad Prism (6.01, GraphPad Software Inc., La Jolla, CA) was used. Differences were defined to be significant at the $P<0.05$ level. 
Table 1. Herd characteristics and milk composition at the day of sampling

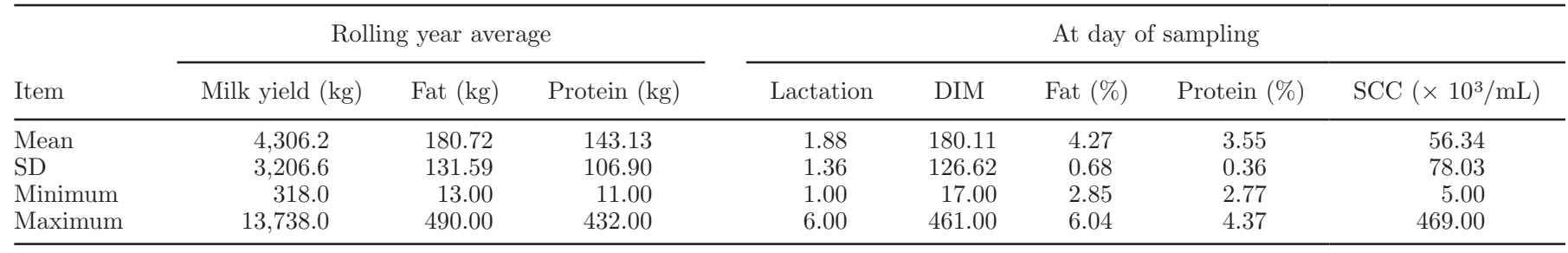

To compare bacterial growth between quarters, growth was expressed as a binomial variable with the number of colony-forming units present after incubation smaller than, or the same as, at the beginning of incubation coded as 0 , and samples with colony-forming units above the number of added colonies before incubation coded as 1 . The expected number of quarter milk samples with bacterial growth per cow was calculated and compared with the number of colony-forming units observed using a chi-squared statistic assuming a binomial distribution. Intra-class correlations were determined using the ANOVA method.

Differences between quarters and between morning and evening milk were analyzed using a mixed model analysis with each milk trait as dependent variable, quarter (ranked from low to high for each milk trait), and time of milking (morning/evening) as explanatory variables, and cow as a random factor. The variation coefficient between triplicates and between cows of milk samples used to detect the effect of IgG titration on in vitro growth of $S$. aureus was determined. In addition, the correlation between spiked IgG concentration and $S$. aureus growth was determined.

Univariable linear analysis was used for every variable against $S$. aureus colony-forming units and $E$. coli colony-forming units and only variables with $P<0.2$ were used in the mixed model analysis to determine whether milk-specific factors influenced in vitro growth of S. aureus, E. coli, or both. To include milk cultures with no detectable growth in the analysis, these cultures were set to 1. Fat, protein, lactose, urea, S. aureus Reynolds specific IgG $\mathrm{I}_{1}$ antibodies, LFn, LP, $\beta$-LG, and SCC were included as continuous variables. Milk contamination (yes/no) and milking time (morning/evening) were included as factorial variables. To correct for repeated observations, quarter was nested within cow and used as a random effect. Variables were assessed for their contribution to the model by the Akaike's information criterion. The model with the lowest Akaike's information criterion was chosen as the best predictor of the data. For all models, residuals were assessed for normal distribution, constant variance, and a mean of 0 . Whenever necessary, data were log-transformed to achieve normality.

\section{RESULTS}

\section{Analysis of Milk Components}

A total of 47 cows were sampled during the morning and the evening milking. Because one cow had only 3 functioning quarters, samples of 187 quarters were available.

An overview of the herd characteristics displayed as the rolling year average as well as the herd and milk characteristics on the day of sampling is given in Table 1. Milk composition of foremilk (lower fat, protein, and lactose concentration) differs as compared with the representative milk sample used for the test day analysis. Because the automated data processing algorithm performed at the milk quality insurance laboratory automatically discarded aberrant values for fat $(<1.5 \%)$, protein $(<2.0 \%)$, and lactose $(<2.5 \%)$, only 152 and 121 values for fat, protein, and lactose were reported for quarters of the morning milking and the evening milking, respectively. The amounts of LF, LP, and $\beta$-LG, as well as $S$. aureus-specific $\operatorname{IgG}_{1}$ concentrations in milk were determined for all quarters. The colostrum of the 4 cows sampled at the day of parturition contained $S$. aureus-specific $\operatorname{IgG}_{1}$ (sample/positive ratios ranging from 0.8 to 1.2 ).

\section{In Vitro Growth Assay}

The actual mean number of colony-forming units added to the quarter milk samples in the in vitro growth assay was $40 \mathrm{cfu}$ per sample (range 22-63) for $S$. aureus and $50 \mathrm{cfu}$ (range 35-68) for E. coli. The colony-forming units detected after in vitro growth per quarter (ranked per cow from lowest to highest) per milking time are presented in Table 2 as median (minimum; maximum). Culturing fresh milk samples on sheep blood agar plates did not reveal bacterial contamination of the collected milk samples. After the in vitro growth assay, 29 milk samples showed growth of other bacterial species on the blood agar plates next to the expected bacterial species, indicating that the in vitro growth assay acted as an enrichment medium for low abundance contaminants. Data regarding milk 
composition are summarized as mean (SD; Table 2). Significant differences between morning and evening milk were detected for all measures with the exception of levels of lactose (Table 3). Protein, fat, urea, LF, $S$. aureus-specific $\operatorname{IgG}_{1}$ and in vitro growth of $E$. coli were higher and $\beta-\mathrm{LG}, \mathrm{LP}, \mathrm{SCC}$ and in vitro growth of $S$. aureus were lower in morning milk compared with evening milk with protein showing the smallest difference (factor 0.15) and LP the biggest difference (factor 14.3) between milkings. Significant differences between quarters were detected for all parameters (Table 3). Comparison between the highest and the lowest quarter revealed differences between quarters ranging from a factor of 0.04 for protein up to a factor of 27.86 for LF. Figure 1 presents the observed numbers of quarter milk samples per cow that showed in vitro bacterial growth together with the expected number of quarters under a binomial distribution. Numbers of observed and expected quarter milk samples with bacterial growth differed significantly as determined by the chi square statistic. The calculated intra-cow correlation coefficient for bacterial growth in quarter samples was 0.267 for S. aureus and 0.107 for E. coli.

Univariate analysis revealed that fat, protein, lactose, urea, SCC, LP, S. aureus-specific $\mathrm{IgG}_{1}$, contamination of the milk sample, and milking time were important predictors for the growth of $S$. aureus and were therefore incorporated into the mixed model analysis. The milking time (morning/evening) was the strongest single predictor $(P<0.000)$. For the growth of $E$. coli, fat, protein, lactose, urea, $S$. aureus-specific $\operatorname{IgG}_{1}$, and milking time were the most important predictors. In this analysis, $S$. aureus-specific $\operatorname{IgG}_{1}$ was the strongest single predictor $(P<0.022)$. The multivariate model best explaining in vitro growth of $S$. aureus (Table 4) contained 4 variables: time of milking, contamination of milk with other bacteria, percentage of fat, and $S$. aureus-specific $\operatorname{IgG}_{1}$ titer. All 4 variables were negatively associated with growth of $S$. aureus. Morning milk was associated with a factor 0.29 decrease as compared with evening milk, a $1 \%$ increase in fat was associated with a factor 0.58 decrease, a $\log _{2}$ increase of $S$. aureus-specific $\mathrm{IgG}_{1}$ was associated with a factor 0.73 decrease and the presence of other bacteria in the milk sample with a factor of 0.25 decrease in growth of $S$. aureus. The multivariate model best explaining in vitro growth of $E$. coli contained the variables time of milking and percentage of fat. The morning milk was positively associated with growth (factor 1.48 increase compared with evening milk) of $E$. coli, whereas the fat percentage showed a negative association (decrease by a factor 0.79 ).

\section{Effect of IgG Titration on In Vitro Growth of S. aureus}

The correlation between IgG concentration and in vitro growth is presented in Figure 2. As the figure indicates, a significant correlation of IgG concentrations with colony-forming unit counts could not be identified. The intra-cow variation coefficient of triplicates of colony-forming units at different IgG concentrations varied from 0.2 to 0.9 . The inter-cow variation coefficient varied from 0.1 to 0.5 .

\section{DISCUSSION}

This study revealed significant differences in milk composition between quarters of a cow. In addition, in vitro bacterial growth was found to be significantly different in quarter milk samples between cows, and between morning and evening milk. Because the quarter differences described in this study were identified in foremilk samples, the magnitude of variation among quarters might be different when using representative milk sample. Experimental inoculation studies circumventing the natural barrier of the teat duct also reported that mastitis susceptibility varies between cows and among quarters of cows (Bramley, 1976) indicating that milk differences may also play a role in mastitis susceptibility in vivo and not only in vitro in striped foremilk samples. These variations have been attributed to SCC (Schukken et al., 1999), the presence of other bacteria (Zadoks et al., 2001), and S. aureus Reynolds specific IgG $\operatorname{Ig}_{1}$ titers (Boerhout et al., 2016). In in vivo inoculation studies, it is difficult to distinguish whether the differences in susceptibility are influenced by factors directly present in milk or by antigen-host interactions inducing an immune response influencing susceptibility. The observed associations between milk components and the deviating growth pattern in vitro of $S$. aureus and E. coli in this study occurred in an in vitro situation and therefore have to be attributed to diurnal differences in morning and evening milk.

When comparing the morning milk and evening milk, significant differences were found in most milk parameters with the exception of lactose. Although we analyzed foremilk instead of representative milk samples, the occurrence of diurnal changes in milk composition are consistent with the literature; however, the magnitude of changes described differs between published studies (Schmidt, 1960; Gilbert et al., 1973; Dohoo and Meek, 1982; Gustafsson and Palmquist, 1993; Quist et al., 2008). The diurnal pattern of SCC is thought to be caused by a dilution effect through milk production between milkings and as a reaction to milking (White 
Table 2. In vitro growth of Staphylococcus aureus and Escherichia coli in fresh quarter milk samples and quantities of milk components in morning milk and evening milk samples ${ }^{1}$

\begin{tabular}{|c|c|c|c|c|c|c|c|c|}
\hline \multirow[b]{2}{*}{ Item } & \multicolumn{2}{|c|}{ S. aureus $(\mathrm{cfu} / \mathrm{mL})$} & \multicolumn{2}{|c|}{ E. $\operatorname{coli}(\mathrm{cfu} / \mathrm{mL})$} & \multicolumn{2}{|c|}{ Fat $(\%)$} & & \\
\hline & Morning $^{2}$ & Evening $^{2}$ & Morning $^{2}$ & Evening $^{2}$ & Morning $^{3}$ & Evening $^{4}$ & & \\
\hline Q1 & $640(0 ; 4,000)$ & $2,560(0 ; 17,280)$ & $40(0 ; 720)$ & $20(0 ; 300)$ & $2.2(0.7)$ & $2.0(0.5)$ & & \\
\hline Q2 & $1,280(0 ; 6,080)$ & $4,480(880 ; 30,720)$ & $110(0 ; 2,400)$ & $120(0 ; 600)$ & $2.4(0.7)$ & $2.3(0.6)$ & & \\
\hline Q3 & $1,840(20 ; 10,880)$ & $5,760(1,520 ; 33,280)$ & $180(0 ; 3,760)$ & $200(0 ; 1,000)$ & $2.7(0.8)$ & $2.6(0.7)$ & & \\
\hline \multirow[t]{3}{*}{ Q4 } & $2,960(640 ; 13,440)$ & $6,880(2,160 ; 42,880)$ & $810(20 ; 24,000)$ & $470(0 ; 2,080)$ & $3.0(0.8)$ & $2.9(0.8)$ & & \\
\hline & \multicolumn{2}{|c|}{ Protein $(\%)$} & \multicolumn{2}{|c|}{ Lactose $(\%)$} & \multicolumn{2}{|c|}{ Urea $(\mathrm{mg} / \mathrm{L})$} & \multicolumn{2}{|c|}{$\mathrm{SCC}\left(\times 10^{3}\right.$ cells $\left./ \mathrm{mL}\right)$} \\
\hline & Morning $^{3}$ & Evening $^{4}$ & Morning $^{3}$ & Evening $^{4}$ & Morning $^{2}$ & Evening $^{2}$ & Morning $^{2}$ & Evening $^{2}$ \\
\hline Q1 & $3.7(0.4)$ & $3.5(0.3)$ & $4.5(0.3)$ & $4.5(0.3)$ & $15.7(5.1)$ & $12.0(3.5)$ & $23.5(45.7)$ & $24.0(46.4)$ \\
\hline Q2 & $3.7(0.4)$ & $3.6(0.4)$ & $4.6(0.2)$ & $4.6(0.3)$ & $16.7(4.9)$ & $13.3(3.9)$ & $38.6(70.1)$ & $45.5(87.3)$ \\
\hline Q3 & $3.9(0.4)$ & $3.7(0.4)$ & $4.6(0.2)$ & $4.6(0.2)$ & $17.2(4.9)$ & $13.9(3.7)$ & $59.5(108.2)$ & $66.6(118.5)$ \\
\hline \multirow[t]{3}{*}{ Q4 } & $3.9(0.3)$ & $3.8(0.3)$ & $4.6(0.2)$ & $4.6(0.2)$ & $18.2(5.1)$ & $14.9(3.9)$ & $97.7(124.1)$ & $105.9(141.3)$ \\
\hline & \multicolumn{2}{|c|}{$\beta-\mathrm{LG}(\mathrm{ng} / \mathrm{mL})$} & \multicolumn{2}{|c|}{ Lactoperoxidase $(\mathrm{U} / \mathrm{mL})$} & \multicolumn{2}{|c|}{ Lactoferrin $(\mathrm{ng} / \mathrm{mL})$} & \multicolumn{2}{|c|}{ S. aureus $\operatorname{IgG}_{1}$ titer } \\
\hline & Morning $^{2}$ & Evening $^{2}$ & Morning $^{2}$ & Evening $^{2}$ & Morning $^{2}$ & Evening $^{2}$ & Morning $^{2}$ & Evening $^{2}$ \\
\hline Q1 & $3.1(0.9)$ & $4.9(1.4)$ & $26.1(6.3)$ & $38.5(9.5)$ & $66.5(52.5)$ & $64.3(52.6)$ & $4.8(1.7)$ & $4.6(1.7)$ \\
\hline Q2 & $3.6(1.0)$ & $5.7(1.4)$ & $27.8(6.3)$ & $41.6(9.9)$ & $73.6(54.9)$ & $70.5(54.8)$ & $5.1(1.7)$ & $4.9(1.7)$ \\
\hline Q3 & $3.9(1.1)$ & $6.3(1.3)$ & $28.8(6.4)$ & $43.9(10.8)$ & $84.8(55.5)$ & $79.4(56.3)$ & $5.4(1.7)$ & $5.2(1.7)$ \\
\hline Q4 & $4.6(1.3)$ & $7.0(1.5)$ & $30.6(7.2)$ & $46.5(11.2)$ & $97.5(57.9)$ & $87.2(59.8)$ & $5.7(1.8)$ & $5.6(1.6)$ \\
\hline
\end{tabular}

Quarters of each cow were ranked from low (Q1) to high (Q4) for each milk trait and grouped accordingly before analysis. The table summarizes data of all quarters collected at

을 morning and evening milking. Data for in vitro growth of $S$. aureus and E. coli are summarized as median (minimum; maximum) and the mean ( \pm SD) for milk components. Q: quarter.

을 187 quarters.

가요 ${ }^{3} 152$ quarters.

$\stackrel{\varrho}{\Sigma} \cdot{ }^{4} 121$ quarters. 
Table 3. Differences between quarters and morning and evening milk estimated for each milk trait using mixed model analysis ${ }^{1}$

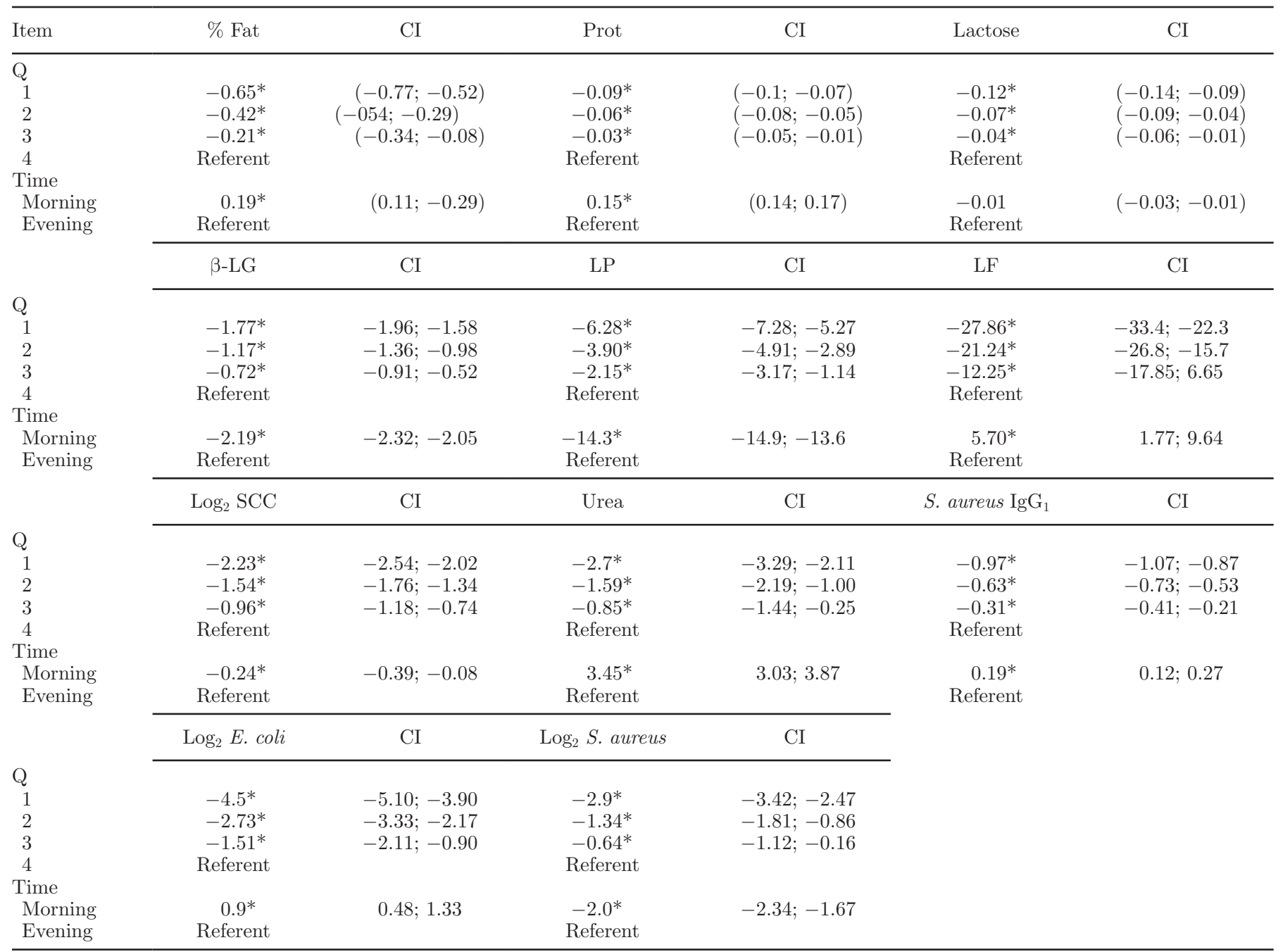

\footnotetext{
${ }^{1}$ Quarters of each cow were ranked from low to high for each milk trait and grouped accordingly before analysis. Q $=$ quarter, Prot $=$ protein, $\mathrm{LP}=$ lactoperoxidase, $\mathrm{LF}=$ lactoferrin, S. aureus $\mathrm{IgG}_{1}=$ Staphylococcus aureus-specific $\mathrm{IgG}_{1}$. Data of SCC, Escherichia coli, and $S$. aureus were $\log _{2}$ transformed.
}

*Significant difference with the reference group.

and Rattray, 1965; Dohoo and Meek, 1982; Nielsen et al., 2005; Forsback et al., 2010; Olde Riekerink et al., 2007). Although the milking interval between evening and morning milking was only slightly longer (13 h) than the interval between morning and evening milking $(11 \mathrm{~h})$, we observed the lowest SCC at morning milking and this has also been reported in in other studies (White and Rattray, 1965; Smith and Schultze, 1967; Forsback et al., 2010). Other studies reported the lowest SCC before the evening milking (Olde Riekerink et al., 2007) or failed to identify a consistent pattern (Quist et al., 2008). Different milking intervals or the use of different type of milk samples might have led to these contrary findings. In high-yielding dairy cows diurnal changes in urea concentration detected in milk have been shown to be related to feed uptake in relation to milking with an increase of milk urea several hours after feeding (Gustafsson and Palmquist, 1993). Although the interval between milking and feed intake in our study was similar, a significant differences between morning and evening milk was detected. Fat concentration in milk has been found to be lower in morning milk when using a composite milk sample, and lower in foremilk samples after a longer interval between milkings (Nielsen et al., 2005; Quist et al., 2008; Forsback et al., 2010). Interestingly, in milk samples analyzed in this study, morning milk samples showed a higher fat concentration compared with evening milk 


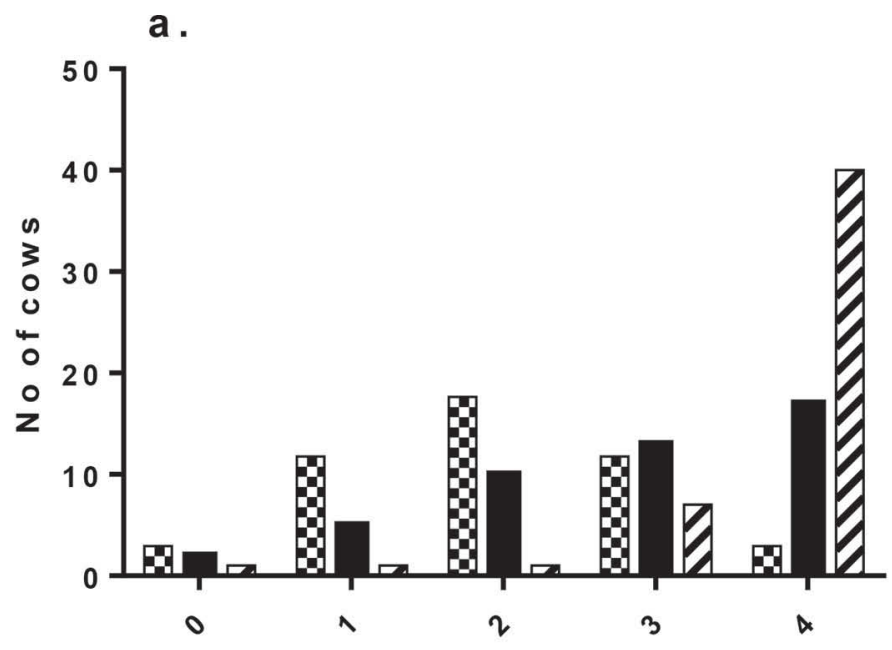

b.

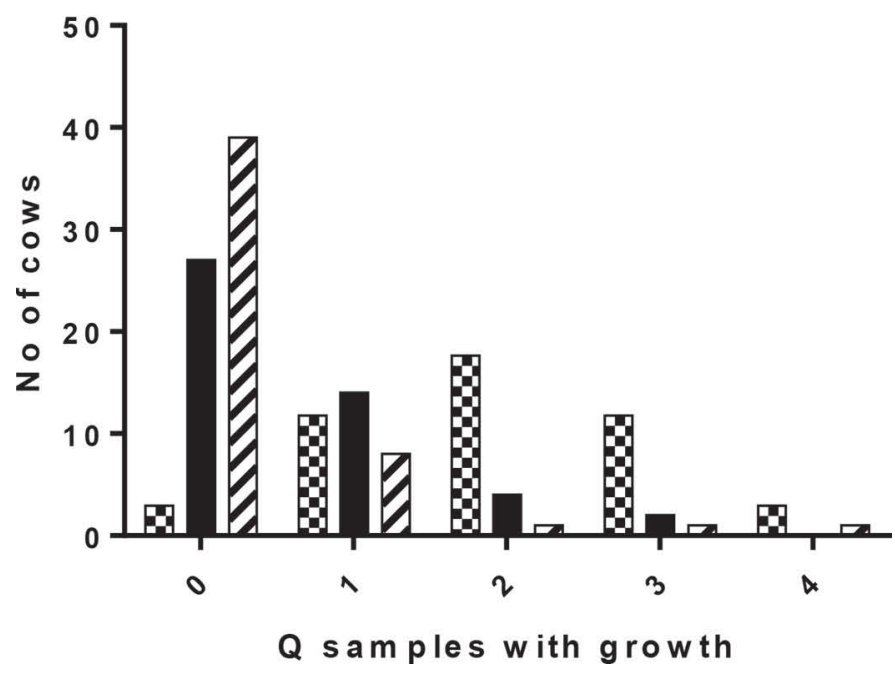

Figure 1. Cows grouped according to the number of quarters milk samples (0 to 4) with growth of Staphylococcus aureus (a) or Escherichia coli (b) in the in vitro growth assay. Growth is presented as a binary indicator $(0=\mathrm{cfu}$ after incubation $\leq$ added $\mathrm{cfu} ; 1=\mathrm{cfu}$ after incubation $>$ added cfu). Bars represent expected number of quarters with bacterial growth under a binomial distribution (checkered), observed number of quarters with bacterial growth in morning milk (black), and observed number of quarters with bacteria growth in evening milk (striped).

samples although the interval between both milkings was relatively similar and foremilk samples were used for analysis. We could not explain this finding.

The LF, $\beta$-LG, and LP produced locally in the udder tissue (Hurley and Rejman, 1993; van Hooijdonk et al., 2000; Piccinini et al., 2005; Huang et al., 2012) are known for their protective antibacterial properties (Bramley, 1976; Hyvonen et al., 2010; Chaneton et al., 2011). We found LF to be present in higher

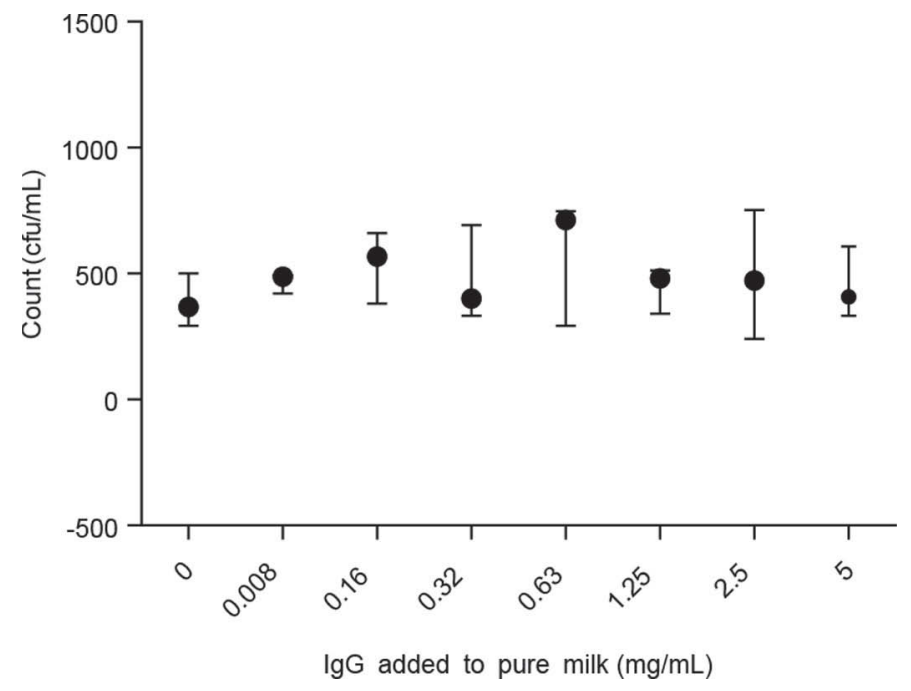

Figure 2. Replication of Staphylococcus aureus in milk spiked with purified IgG on top of natural IgG levels $(<1 \mathrm{mg} / \mathrm{mL})$. Data represent the median $S$. aureus replication with the interquartile ranges of milk samples of 3 cows.

concentrations in morning milk, whereas LP and $\beta$-LG were higher in evening milk. So far, explanations for differences in concentrations given in literature were restricted to age, lactation status, and SCC (Hurley and Rejman, 1993; Fonteh et al., 2002; Hagiwara et al., 2003; Hyvonen et al., 2010). How these diurnal differences occur is unclear. Although in vitro bacterial growth in milk differed significantly between cows and between morning and evening milk samples, statistical analysis revealed no association with LF, $\beta-\mathrm{LG}$, or LP.

Immunoglobulins present in milk during lactation are mainly of the $\mathrm{IgG}_{1}$ isotype that are selectively translocated from serum into the mammary gland (Korhonen

Table 4. Estimation of the association between in vitro bacterial growth and milk components ${ }^{1}$

\begin{tabular}{lcc}
\hline Variable & Estimate & CI \\
\hline Staphylococcus aureus & & \\
$\quad$ Time of milking & -0.541 & $-0.665 ;-0.045$ \\
$\quad$ Morning & Referent & $-0.319 ;-0.147$ \\
$\quad$ Evening & -0.233 & $-0.252 ;-0.016$ \\
$\%$ fat & -0.134 & \\
S. aureus-specific IgG & & \\
Presence of other bacteria & 0.244 & $0.076 ;-0.412$ \\
$\quad$ No & Referent & \\
$\quad$ Yes & & \\
Escherichia coli & & \\
Time of milking & 0.171 & $0.034 ; 0.308$ \\
$\quad$ Morning & Referent & $-0.205 ; 0.002$ \\
$\quad$ Evening & -0.102 & \\
\% fat &
\end{tabular}

${ }^{1}$ Estimates are gained by mixed model analyses. 
et al., 2000). The IgG concentrations are not influenced by quarter location or blood serum concentration when measured once a day (Caffin et al., 1983; Boerhout et al., 2016). However, in this study we showed that the $\mathrm{IgG}_{1}$ antibody titer specific for $S$. aureus was statistically different among quarters of a cow, and when measured twice a day, we detected diurnal differences with concentrations higher in evening milk compared with morning milk. A significant negative association between $S$. aureus-specific antibody concentrations in milk and replication of $S$. aureus was identified. Because we did not perform a vaccination against $S$. aureus, titers are thought to be induced following natural exposure to $S$. aureus. Our data support findings of an in vivo study where susceptibility to experimentally induced $S$. aureus mastitis was analyzed and shown to be negatively associated with $S$. aureus-specific $\mathrm{IgG}_{1}$ levels in milk (Boerhout et al., 2016). These findings support the ongoing efforts of developing a vaccine against $S$. aureus mastitis. However, our attempt to influence bacterial growth by enhancing IgG concentrations in milk up to 5 times the natural level by simple titrations of purified antibodies did not successfully reproduce the growth inhibitory effect. Although the final $S$. aureusspecific $\operatorname{IgG}_{1}$ concentration in spiked milk samples was not determined, an increase must have been achieved because colostrum samples used for purification were confirmed to contain high levels of $S$. aureus-specific antibodies and colostrum contains mainly antibodies of the $\mathrm{IgG}_{1}$ isotype (Korhonen et al., 2000). It is likely that other factors not measured in this study such as complement components for example should have been present in enhanced concentrations as well to let immunoglobulins effectively hamper $S$. aureus growth.

Observed and expected bacterial growth of both $S$. aureus and $E$. coli in quarter milk samples between cows differed significantly (Figure 1), indicating the presence of cow-specific differences which were supported by the intra-cow correlation coefficients. Cow characteristics influencing susceptibility to mastitis were previously identified in vivo where cows were experimentally infected with $S$. aureus and clustering within cows occurred (Schukken et al., 1999). The in vitro bacterial growth data presented here indicate that milk composition without antigen-host interaction plays a role in altering bacterial growth. To adjust for the intra-cow correlation in statistical analysis, cow was used as a random factor.

Contrary to data of in vivo growth of $S$. aureus after experimental inoculation where fat concentration was positively associated with bacterial replication (Boerhout et al., 2016), in this study fat was associated negatively with replication of $S$. aureus as well $E$. coli.
A $1 \%$ increase in fat was associated with a significant decrease of the number of colony-forming units and this was stronger for $S$. aureus than for $E$. coli. Two explanations can be given for the direct inhibitory effect of fat on bacterial growth. First, a higher fat concentration in milk has been described to be accompanied by a higher amount of complement (Tamplin, 2002; Maye et al., 2015). Presence and function of complement factors in milk were not analyzed in this study and therefore its role in the in vitro growth assay could not be determined. Second, agitation of milk leads to activation of lipolysis leading to the presence of fatty acids with antimicrobial properties (Isaacs et al., 1995; Sprong et al., 2001; Ray et al., 2013). Handling of milk during sampling and assay preparation most likely activated lipolysis by disrupting the milk fat globule and thereby exposing the lipid substrate to the lipase (Deeth, 2006; Ray et al., 2013). It is unlikely that the inhibitory effect on replication caused by lipolysis occurs in vivo.

The contrary time effect, $S$. aureus replicating in lower numbers in morning milk whereas E. coli replication was higher, was surprising and could not be explained.

Contamination of milk samples incorporated as a binary variable (other bacteria present yes/no) was negatively associated with replication of $S$. aureus in milk in vitro, which is consistent with literature where inhibition of staphylococcal replication by different bacterial species in the mammary gland as well as in vitro has been described (DiGiacinto and Frazier, 1966; Kao and Frazier, 1966; Lam et al., 1997; Schukken et al., 1999). In vivo, the presence of other staphylococci and Corynebacterium bovis has been found to reduce the risk of mastitis (Rainard and Poutrel, 1988; Nickerson and Boddie, 1994). In vitro, the presence of commensal bacteria in human breast milk was shown to reduce growth of $S$. aureus and natural background flora has been considered as a useful tool to prevent redundant growth of staphylococci in food products (Vold et al., 2000; Heikkila and Saris, 2003). For E. coli replication, a negative association with the presence of other bacteria has not been described so far and was also not present is this study.

In conclusion, almost all measured milk components differed significantly between quarters and showed a diurnal pattern. Although morning and evening milk showed a clear difference in bacterial replication, none of the determined milk parameters were clearly associated with the exception of fat. Confirming that $S$. aureus-specific immunoglobulins reduce $S$. aureus growth in milk of unvaccinated cows is emphasizing approaches to enhance udder immunity against $S$. aureus by increasing specific antibody titers in milk through vaccination. The exact mechanism leading to the as- 
sociation between $S$. aureus-specific $\operatorname{IgG}_{1}$ concentration and decreased $S$. aureus replication could not be identified. Future studies should look into milk composition in more detail to identify natural antibacterial substances that could be used to enhance udder health.

\section{ACKNOWLEDGMENTS}

The authors thank the animal caretakers of the Faculty of Veterinary Medicine at Utrecht University for their support during milk sampling. This study was financed by the Alternatives for Antibiotics (ALTANT) project subsidized by the Ministry of Economic Affairs, Agriculture and Innovation of the Dutch government.

\section{REFERENCES}

Albus, A., R. D. Arbeit, and J. C. Lee. 1991. Virulence of Staphylococcus aureus mutants altered in type 5 capsule production. Infect. Immun. 59:1008-1014.

Barkema, H. W., H. A. Deluyker, Y. H. Schukken, and T. J. Lam. 1999. Quarter-milk somatic cell count at calving and at the first six milkings after calving. Prev. Vet. Med. 38:1-9.

Boerhout, E. M., A. P. Koets, J. C. M. Vernooij, T. G. T. Mols-Vorstermans, P. J. M. Nuijten, V. P. M. G. Rutten, J. J. E. Bijlsma, and S. W. F. Eisenberg. 2016. Staphylococcus aureus reisolation from bovine milk following experimental inoculation is influenced by the fat percentage and specific IgG1 titer in milk. J. Dairy Sci. http://dx.doi.org/10.3168/jds.2015-10648.

Bramley, A. J. 1976. Variations in the susceptibility of lactating and non-lactating bovine udders to infection when infused with Escherichia coli. J. Dairy Res. 43:205-211.

Breen, J. E., M. J. Green, and A. J. Bradley. 2009. Quarter and cow risk factors associated with the occurrence of clinical mastitis in dairy cows in the United Kingdom. J. Dairy Sci. 92:2551-2561.

Caffin, J. P., B. Poutrel, and P. Rainard. 1983. Physiological and pathological factors influencing bovine immunoglobulin G1 concentration in milk. J. Dairy Sci. 66:2161-2166.

Chaneton, L., J. M. Perez Saez, and L. E. Bussmann. 2011. Antimicrobial activity of bovine beta-lactoglobulin against mastitis-causing bacteria. J. Dairy Sci. 94:138-145.

Deeth, H. C. 2006. Lipoprotein lipase and lipolysis in milk. Int. Dairy J. 16:555-562.

DiGiacinto, J. V., and W. C. Frazier. 1966. Effect of coliform and Proteus bacteria on growth of Staphylococcus aureus. Appl. Microbiol. 14:124-129.

Dohoo, I. R., and A. H. Meek. 1982. Somatic cell counts in bovine milk. Can. Vet. J. 23:119-125.

Fonteh, F. A., A. S. Grandison, and M. J. Lewis. 2002. Variations of lactoperoxidase activity and thiocyanate content in cows' and goats' milk throughout lactation. J. Dairy Res. 69:401-409.

Forsback, L., H. Lindmark-Mansson, A. Andren, M. Akerstedt, L. Andree, and K. Svennersten-Sjaunja. 2010. Day-to-day variation in milk yield and milk composition at the udder-quarter level. J. Dairy Sci. 93:3569-3577.

Gilbert, G. R., G. L. Hargrove, and M. Kroger. 1973. Diurnal variations in milk yield, fat yield, milk fat percentage, and milk protein percentage of Holstein-Friesian cows. J. Dairy Sci. 56:409-410.

Green, M. J., A. J. Bradley, G. F. Medley, and W. J. Browne. 2007. Cow, farm, and management factors during the dry period that determine the rate of clinical mastitis after calving. J. Dairy Sci. 90:3764-3776.

Gustafsson, A. H., and D. L. Palmquist. 1993. Diurnal variation of rumen ammonia, serum urea, and milk urea in dairy cows at high and low yields. J. Dairy Sci. 76:475-484.
Hagiwara, S., K. Kawai, A. Anri, and H. Nagahata. 2003. Lactoferrin concentrations in milk from normal and subclinical mastitic cows. J. Vet. Med. Sci. 65:319-323.

Heikkila, M. P., and P. E. Saris. 2003. Inhibition of Staphylococcus aureus by the commensal bacteria of human milk. J. Appl. Microbiol. 95:471-478.

Huang, Y. Q., K. Morimoto, K. Hosoda, Y. Yoshimura, and N. Isobe. 2012. Differential immunolocalization between lingual antimicrobial peptide and lactoferrin in mammary gland of dairy cows. Vet. Immunol. Immunopathol. 145:499-504.

Hurley, W. L., and J. J. Rejman. 1993. Bovine lactoferrin in involuting mammary tissue. Cell Biol. Int. 17:283-289.

Hyvonen, P., T. Haarahiltunen, T. Lehtolainen, J. Heikkinen, R. Isomaki, and S. Pyorala. 2010. Concentrations of bovine lactoferrin and citrate in milk during experimental endotoxin mastitis in early- versus late-lactating dairy cows. J. Dairy Res. 77:474-480.

Isaacs, C. E., R. E. Litov, and H. Thormar. 1995. Antimicrobial activity of lipids added to human milk, infant formula, and bovine milk. J. Nutr. Biochem. 6:362-366.

Kao, C. T., and W. C. Frazier. 1966. Effect of lactic acid bacteria on growth of Staphylococcus aureus. Appl. Microbiol. 14:251-255.

Keefe, G. 2012. Update on control of Staphylococcus aureus and Streptococcus agalactiae for management of mastitis. Vet. Clin. North Am. Food Anim. Pract. 28:203-216.

Korhonen, H., P. Marnila, and H. S. Gill. 2000. Milk immunoglobulins and complement factors. Br. J. Nutr. 84(Suppl. 1):S75-S80.

Lam, T. J., Y. H. Schukken, J. H. van Vliet, F. J. Grommers, M. J. Tielen, and A. Brand. 1997. Effect of natural infection with minor pathogens on susceptibility to natural infection with major pathogens in the bovine mammary gland. Am. J. Vet. Res. 58:17-22.

Maye, S., C. Stanton, G. F. Fitzgerald, and P. M. Kelly. 2015. Detection and characterisation of Complement protein activity in bovine milk by bactericidal sequestration assay. J. Dairy Res. 82:328-333.

Nickerson, S. C., and R. L. Boddie. 1994. Effect of naturally occurring coagulase-negative staphylococcal infections on experimental challenge with major mastitis pathogens. J. Dairy Sci. 77:2526-2536.

Nielsen, N. I., T. Larsen, M. Bjerring, and K. L. Ingvartsen. 2005. Quarter health, milking interval, and sampling time during milking affect the concentration of milk constituents. J. Dairy Sci. 88:3186-3200.

Olde Riekerink, R. G., H. W. Barkema, W. Veenstra, F. E. Berg, H. Stryhn, and R. N. Zadoks. 2007. Somatic cell count during and between milkings. J. Dairy Sci. 90:3733-3741.

Peton, V., and Y. Le Loir. 2014. Staphylococcus aureus in veterinary medicine. Infect. Genet. Evol. 21:602-615.

Piccinini, R., E. Binda, M. Belotti, G. Casirani, and A. Zecconi. 2005. Comparison of blood and milk non-specific immune parameters in heifers after calving in relation to udder health. Vet. Res. 36:747757.

Quist, M. A., S. J. LeBlanc, K. J. Hand, D. Lazenby, F. Miglior, and D. F. Kelton. 2008. Milking-to-milking variability for milk yield, fat and protein percentage, and somatic cell count. J. Dairy Sci. 91:3412-3423.

Rainard, P., and B. Poutrel. 1988. Effect of naturally occurring intramammary infections by minor pathogens on new infections by major pathogens in cattle. Am. J. Vet. Res. 49:327-329.

Ray, P. R., K. Chatterjee, C. Chakraborty, and P. K. Ghatak. 2013. Lipolysis of milk: A review. Int. J. Agric. Sci. Vet. Med. 1:58-74.

Schmidt, G. H. 1960. Effect of milking intervals on the rate of milk and fat secretion. J. Dairy Sci. 43:213-219.

Schukken, Y. H., F. J. Grommers, D. van de Geer, H. N. Erb, and A. Brand. 1991. Risk factors for clinical mastitis in herds with a low bulk milk somatic cell count. 2. Risk factors for Escherichia coli and Staphylococcus aureus. J. Dairy Sci. 74:826-832.

Schukken, Y. H., K. E. Leslie, D. A. Barnum, B. A. Mallard, J. H. Lumsden, P. C. Dick, G. H. Vessie, and M. E. Kehrli. 1999. Experimental Staphylococcus aureus intramammary challenge in late lactation dairy cows: Quarter and cow effects determining the probability of infection. J. Dairy Sci. 82:2393-2401. 
Slettbakk, T., A. Jørstad, T. B. Farver, and J. C. Holmes. 1995. Impact of milking characteristics and morphology of udder and teats on clinical mastitis in first- and second-lactation Norwegian cattle. Prev. Vet. Med. 24:235-244.

Smith, G. W., R. L. Lyman, and K. L. Anderson. 2006. Efficacy of vaccination and antimicrobial treatment to eliminate chronic intramammary Staphylococcus aureus infections in dairy cattle. J. Am. Vet. Med. Assoc. 228:422-425.

Smith, J. W., and W. D. Schultze. 1967. Variation in cell content of milk associated with time of sample collection. I. Diurnal variation. J. Dairy Sci. 50:1083-1087.

Sprong, R. C., M. F. E. Hulstein, and R. Van der Meer. 2001. Bactericidal activities of milk lipids. Antimicrob. Agents. Ch. 45:12981301.

Tamplin, M. L. 2002. Growth of Escherichia coli O157:H7 in raw ground beef stored at 10 degrees $\mathrm{C}$ and the influence of competi- tive bacterial flora, strain variation, and fat level. J. Food Prot. 65:1535-1540.

van Hooijdonk, A. C., K. D. Kussendrager, and J. M. Steijns. 2000. In vivo antimicrobial and antiviral activity of components in bovine milk and colostrum involved in non-specific defence. Br. J. Nutr. 84(Suppl. 1):S127-S134.

Vold, L., A. Holck, Y. Wasteson, and H. Nissen. 2000. High levels of background flora inhibits growth of Escherichia coli O157:H7 in ground beef. Int. J. Food Microbiol. 56:219-225.

White, F., and E. A. Rattray. 1965. Diurnal variation in the cell content of cows' milk. J. Comp. Pathol. 75:253-261.

Zadoks, R. N., H. G. Allore, H. W. Barkema, O. C. Sampimon, G. J. Wellenberg, Y. T. Grohn, and Y. H. Schukkent. 2001. Cow- and quarter-level risk factors for Streptococcus uberis and Staphylococcus aureus mastitis. J. Dairy Sci. 84:2649-2663. 